\title{
Geomorfología del cantón de Siquirres, Costa Rica
}

\section{Geomorphology of the canton of Siquirres, Costa Rica}

\author{
Luis Nelson Arroyo González ${ }^{1}$ \\ Universidad Nacional, Costa Rica
}

\begin{abstract}
Resumen
Este artículo forma parte de un diagnóstico ambiental que representa una sección de un levantamiento para el Plan Regulador de Siquirres. Con el propósito de caracterizar aspectos geológicos y geomorfológicos, se acude al uso de reportes técnicos, mapas temáticos, fotografías aéreas y trabajo de campo. Se realiza una delimitación y clasificación de formas de relieve; las cuales una vez individualizadas, se les describen tipos de amenazas naturales potenciales. Este levantamiento es un insumo para las tareas de ordenamiento del territorio cantonal mediante el Plan Regulador.
\end{abstract}

Palabras clave: Geomorfología, amenazas naturales, vulnerabilidad

\begin{abstract}
This article is part of an environmental diagnosis that represents a section of a survey intended to be used for the creation of the Regulatory Plan (i.e., land use regulations) for the canton of Siquirres. With the intention of characterizing geological and geomorphological aspects, use was made of technical reports, thematic maps, aerial photographs and field work activities. Demarcation and classification of landforms was carried out and, thereafter, each landform was assigned potential natural hazards. The survey constitutes an input for realizing the tasks involved in cantonal territorial planning through the use of the Regulatory Plan instrument.
\end{abstract}

Keywords: Geomorphology; natural hazards; vulnerability

1 Profesor e Investigador Jubilado Escuela de Geografía Universidad Nacional, Costa Rica. Maestría en Recursos Naturales y Desarrollo Sostenible. Postgrado en Levantamientos Geomorfológicos, ITC Holanda. Especialista en Fotointerpretación para Levantamientos Regionales, Centro Interamericano de Fotointerpretación (CIAF) Bogotá, Colombia.. Correo electrónico: luis.arroyo.gonzalez@una.cr/nelson.arroyo2008@gmail.com. (iD https://orcid.org/0000-0003-0294-1034 
Luis Nelson Arroyo González

\section{Introducción}

\section{Ubicación y localización del cantón de Siquirres}

Las coordenadas geográficas medias del cantón de Siquirres son $10^{\circ} 08^{\prime} 45^{\prime \prime}$ de latitud norte y $83^{\circ} 29^{\prime} 50^{\prime}$ ' longitud oeste. Por el oeste limita con los cantones de Guácimo y Pococí; por el este con Matina, mientras que por el sur su límite es con Turrialba y por el norte con el Mar Caribe. Este territorio administrativo con una superficie de $860,10 \mathrm{~km} 2$ es el cuarto cantón en extensión de la provincia de Limón, pues ocupa el $9.36 \%$ del área total de la provincia. Su anchura máxima es de $52 \mathrm{~km}$ en dirección noreste a suroeste, medidos desde la desembocadura del río Pacuare en el mar Caribe hasta la naciente del río Destierro en la Sierra Volcánica Central a 2379 metros de altitud, siendo este punto el de mayor elevación en el cantón.

Su territorio se emplaza en parte de la fachada este de la Cordillera de Talamanca y en correspondencia con las tierras que miran hacia el caribe costarricense. Un 70\% del territorio está conformado por abanicos y llanuras aluviales producto del arrastre y depósito de sedimentos transportados por ríos que, como el Reventazón y el Pacuare, tienen su nacimiento fuera de los límites cantonales. Son tierras planas, con limitaciones locales por mal drenaje sobre todo en los sectores cercanos al mar y en aquellas áreas adyacentes a ríos de alta sinuosidad y corrientes divagantes. El 30\% restante está constituido por áreas montañosas y abruptas, fuertemente afectadas por procesos erosivos Cerca de $8.5 \%$ de este porcentaje pertenece a terrenos que oscilan entre un $30 \%$ a $60 \%$ de pendiente, de laderas altamente inestables y con procesos erosivos activos con abundante aporte de materiales hacia los cursos fluviales. Esta área se conceptualiza como deslizamiento semiactivo y en extensión alcanza cerca de $47 \mathrm{~km}^{2}$.

\section{Método}

En una etapa preliminar se ubicaron sobre el territorio del cantón 42 fotografías a color natural del Proyecto TERRA a escala 1:40.000 (Instituto Geográfico Nacional, 1998). Estas imágenes, con una cobertura territorial aproximada de $84 \mathrm{~km}^{2}$ por foto, abarcaron también los territorios limítrofes de esta unidad cantonal, lo cual facilita delimitar cuencas hidrográficas y extrapolar unidades de relieve de las áreas vecinas mediante el análisis estereoscópico. 
En función de las aplicaciones, de los lineamientos del levantamiento, del análisis y mapeo geomorfológico a realizar, se aborda esta investigación desde dos perspectivas complementarias. La primera alude a estudios sistemáticos y que se plasman en mapas geomorfológicos analíticos (Van Zuidam, 1986). De acuerdo con este autor, este tipo de enfoque es principalmente monodisciplinario y, además de dar información acerca de las formas del terreno y de los procesos exógenos, enfatiza en morfogénesis y morfocronología, incluyendo también aspectos morfoestructurales. En la segunda, se plantean estudios entre el plano geomorfológico por un lado y la diversidad de elementos del medio ambiente por el otro, ubicando así el terreno dentro de un levantamiento ecológico del paisaje o medioambiental que resulta en un mapa sintético u holístico (Verstappen, 1983).

La delimitación de las unidades geomórficas se hace de acuerdo con los siguientes criterios: proceso geológico dominante en la creación de la forma, uniformidad en el tipo de relieve y tipo litológico (Van Zuidam, 1986).

El soporte litológico lo constituyó el mapa geológico escala 1:200.000 elaborado por la Dirección de Geología y Minas y Petróleo, así como el Mapa Geomorfológico de Costa Rica de Rodolfo Madrigal (1980) a la misma escala del precedente. Para trasladar el detalle observado en las fotos aéreas se utilizaron las hojas topográficas Tucurrique, Matina, Barbilla, Parismina, y Bonilla, escala 1:50.000 del Instituto Geográfico Nacional (1967). Se incluyó información sobre amenazas naturales proveniente de mapas elaborados por la Comisión Nacional de Emergencia (1994).

Se consultaron, además, informes técnicos relacionados con estudios físicos en el área y constataciones de detalle en giras al campo. La elaboración de unidades con base en el proceso geológico dio como resultado la subdivisión del cantón en treinta unidades agrupadas en: formas de sedimentación aluvial, formas de origen marino, formas por remoción en masa $\mathrm{y}$ formas por denudación. Posteriormente, estas se reagruparon y permitieron construir apoyos visuales en forma de gráficos y de tablas. Cada una de estas unidades geomórficas fue a su vez subdividida de acuerdo con el tipo de roca madre, a la forma de sus laderas, procesos dominantes, valles o divisorias y otros rasgos geomórficos como la magnitud de las pendientes (Verstappen, 1983). Este trabajo forma parte de los insumos que se aportaron para el Plan Regulador del cantón período 2007-2010. 
El mapa geomórfico resume así las características sobresalientes de las formas de relieve, así como las restricciones y potencialidades que su ocupación plantea.

\section{Geología cantón de Siquirres}

Materiales del Terciario y Cuaternario se alternan con dominancia de estos últimos. Al Terciario pertenecen rocas de origen sedimentario e intrusivo. Las sedimentarias datan de las épocas oligoceno, mioceno y plioceno. Del Terciario se identifican materiales indiferenciados, ubicados al sureste de la región, próximos al límite con el cantón de Turrialba. Las rocas del Mioceno están representadas por la formación Uscari, compuesta por lutitas de tonalidades oscuras y que se sitúan en el sector aledaño al sitio Huacas y en la margen sur del curso inferior del río Bonilla hasta el poblado Lomas. De las rocas sedimentarias del Plioceno se encuentran la formación Suretka y materiales indiferenciados. Está constituida por conglomerados, que van desde partículas de arcilla hasta bloques de más de un metro de diámetro, como basaltos, andesitas y cuarzodioritas cementados por sílice, con intercalaciones de unos pocos estratos de areniscas y lutiras ligníticas, de ambiente litoral y continental. Se ubican desde el sector sur de la villa de Cairo y el poblado Babilonia hasta la ladera noroeste del cerro Roca, así como desde las márgenes de la quebrada Lajas hasta el sector aledaño al poblado Calvario. Los materiales indiferenciados se localizan en la zona comprendida por el sector sur de la ciudad de Siquirres, el alto Berlín, confluencia de los ríos Rubio y Reventazón y la ladera suroeste de fila Amador, lo mismo que en la ladera oeste de la fila anterior, en dirección este hasta el límite con el cantón de Matina. Las rocas intrusivas del Mioceno corresponden a los intrusivos ácidos de la Cordillera de Talamanca, como dioritas cuárcicas y granodioritas, también gabros y granitos, y se ubican en las cercanías del cerro Mercedes. Entre los materiales del Cuaternario, se localizan rocas de origen volcánico y sedimentario. Las primeras son de las épocas pleistoceno y holoceno. Se ubican dentro de este grupo lahares, situados al oeste de la región, próximos al límite con el cantón de Guácimo; así como desde villa Germania hasta la ladera norte del cerro Roca. A las rocas volcánicas del Holoceno corresponden edificios volcánicos recientes y actuales, ubicándose al sureste del cantón, a partir del cerro Roca. Los materiales sedimentarios de la época citada 
corresponden a pantanos ubicados al noreste de la región, próximos al límite con el cantón de Pococí y el litoral Caribe, así como depósitos fluviales, coluviales y costeros recientes, localizados en la mayor superficie del cantón, situados al norte de este a partir de la vía férrea (Ministerio de Recursos Naturales Energía y Minas, 1980).

\section{Geomorfología del cantón de Siquirres}

El territorio del cantón de Siquirres posee una extensión de 860,19 $\mathrm{km}^{2}$ y se asienta sobre seis clases de unidades geomorfológicas. Estas deben su origen a procesos de sedimentación aluvial, de naturaleza tectónico y erosivo, de fuente volcánica, a remoción en masa, a litoral de origen marino y de origen estructural (Ver mapa No. 1).

Mapa No. 1. Geomorfología del cantón de Siquirres.

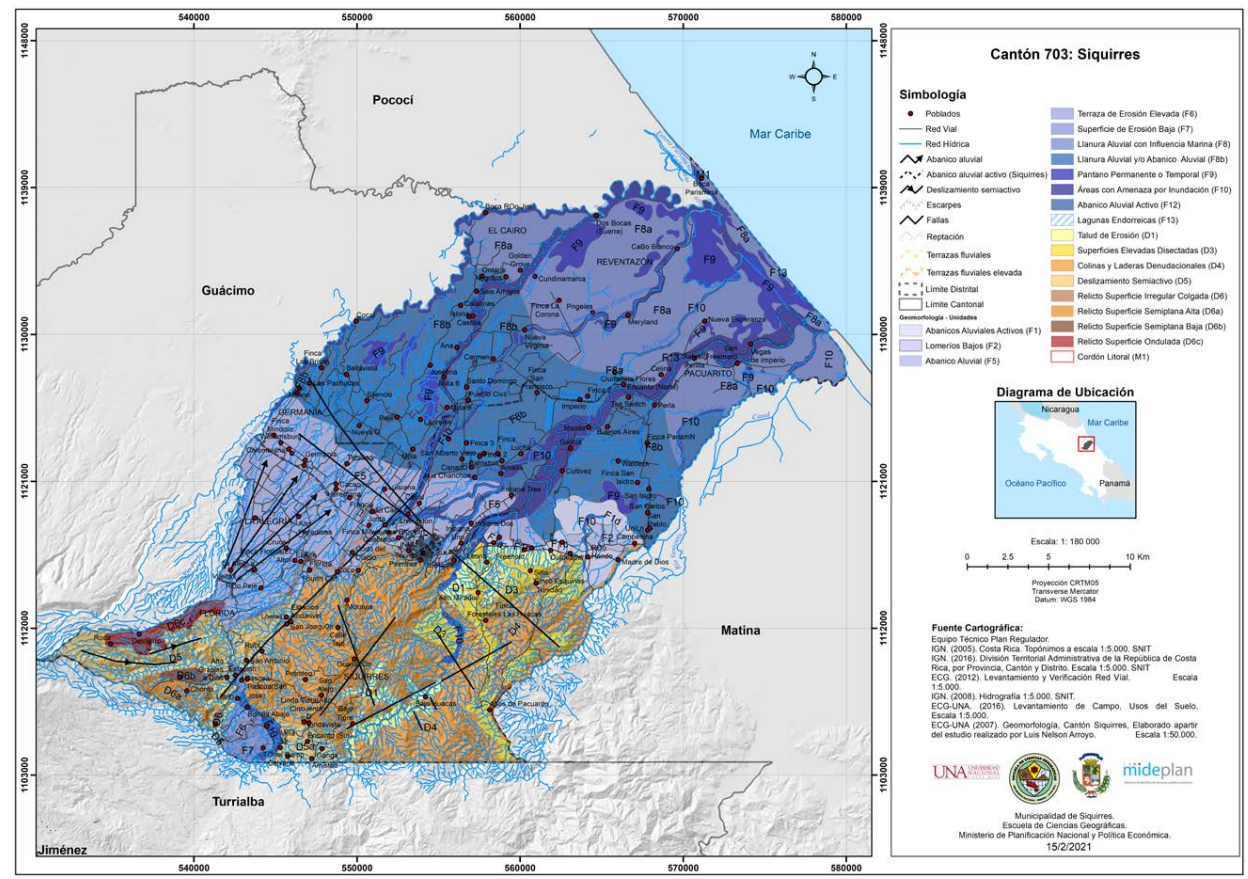




\section{Unidades de sedimentación aluvial}

F8a. Llanura aluvial (influencia marina en suelos)

F8b. Llanura aluvial y/o coalescencia de abanicos aluviales

La sub-unidad llanura aluvial San Carlos y el Caribe representa en el cantón de Siquirres una prolongación de una extensa planicie que se erige al pie de los relieves montañosos cuya fachada se orienta hacia el mar Caribe (Madrigal, 1980).

En función de los procesos y las formas que estos originan es necesario subdividir esta llanura, por un lado, en una división que conforma la sección distal de una coalescencia de abanicos aluviales y, por otro, en la parte de la llanura aluvial que cerca de la costa puede tener influencia marina en la formación de suelos y relieves.

Tanto la llanura como la sección distal de los abanicos presentan una superficie plana que en algunos sitios es ligeramente ondulada. En gran parte esta ondulación es ocasionada por un paleo relieve que corresponde con tobas y corrientes de lodo en mayor grado de meteorización que las rocas superficiales y que tienen, por efectos de erosión, la forma de lomeríos bajos sobre los cuales se depositaron materiales aluviales recientes (ídem).

La monotonía de la llanura es interrumpida en las vecindades de los ríos por un micro relieve producto de la erosión y del depósito fluvial. Se observan abundantes canales abandonados. La parte de la unidad que puede presentar en sus suelos cierto grado de salinidad por su reciente formación y su vecindad al océano puede haberse originado por un relleno que se efectuó en parte en agua de mar.

Sobre la segunda sección denominada llanura aluvial se sitúan las localidades de Encanto al norte de Golden Grove, finca Panamá y Estero Madre de Dios; así como Suerre, Caño Blanco, Nueva Esperanza, San Rafael y la Perla, entre otros.

Peligros potenciales naturales asociados con estas morfologías:

F8: inundaciones. Influencia directa de eventos meteorológicos por huracanes. 


\section{F5. Abanico río Reventazón}

En el caso propiamente del abanico del río Reventazón y que modela un amplio sector del relieve en el cantón, su vértice se localiza a unos $6 \mathrm{~km}$ al oeste de Siquirres. Su pendiente es de unos $6^{\circ}(10 \%)$ cerca de su vértice que se ubica a unos $7 \mathrm{~km}$ al SW de la estación del Ferrocarril, llamada Junta.

La subunidad abanico aluvial del río Reventazón se localiza en la zona comprendida por ciudad Siquirres, así como Cairo, Lousiana, Brooklin, Junta y Tres Millas, entre otros.

La sección denominada distal se representa en una coalescencia de abanicos aluviales cuyo origen está en la transición del sector montañoso a la planicie. Esta a su vez se subdivide en una zona más alta y que está cerca de sus vértices en donde hay mayor influencia de roca volcánica in situ y la zona más baja en donde esa influencia es menor o desaparece.

Una serie de ríos que descienden la Cordillera de Talamanca por el noreste tales como el Guácimo, Guacimito, Novillos, Parismina, Destierro y Reventazón —estos tres últimos dentro de la jurisdicción de Siquirresdan origen a la formación de abanicos aluviales, los cuales junto con los abanicos aluviales de los ríos Chirripó-Sucio, Toro Amarillo, Reventazón y Chirripó y Zent; han contribuido a desarrollar un verdadero pie de monte.

$\mathrm{Su}$ forma es en conjunto plana, paralela a la cordillera con una pendiente de $6^{\circ}(11 \%$ en la sección alta, mientras que en la parte baja la pendiente es de $1^{\circ}$ a $2^{\circ}(-1 \%-3 \%)$. Esta pendiente está dirigida siempre en forma general de menos de $1^{\circ}(-1 \%)$, o sea, un promedio de $3,5 \mathrm{~cm}$ por cada 100 metros de distancia. El corte de los ríos efectuado en la zona alta de los abanicos es profundo y de laderas verticales. La superficie de los abanicos es plana con muchas vías de drenaje superficial de pocos metros de corte. Los espacios interfluviales son angostos, no mayores de 200 metros. La llanura y los abanicos se confunden imperceptiblemente. Los cauces principales que cortan la llanura tienen un valle ancho, con orillas casi siempre de uno o dos metros sobre el nivel del río. Su patrón es meándrico. Como una consecuencia de su escasa pendiente, la presencia de terrenos pantanosos es frecuente. Esto se pone de manifiesto cerca de la costa, en cuya cercanía abundan los terrenos con mal drenaje.

En el área de los abanicos, hay una dominancia de lahares y corrientes de lodo, lo cual hace que el terreno esté formado de gran cantidad de bloques de roca lávica, dentro de una matriz arenosa, o arcillosa. En la 
sección más alta puede existir la presencia de rocas volcánicas, como lavas y piroclastos intercalados en la secuencia, que se han formado de estos abanicos. La sección distal muestra únicamente fracciones finas de rocas lávicas dentro de una matriz arcillosa, pero en algunos sitios es frecuente que a tres metros de profundidad se evidencie la presencia de rocas tobáceas o de corrientes de lodo, con mayor grado de meteorización que las superficiales. Esto en parte puede ser una de las razones del mal drenaje local. Estas rocas más viejas y muy meteorizadas afloran en ciertas áreas, lo que ocasiona un cambio brusco en la condición del suelo. Tanto los abanicos como la llanura en sí han sido originados por el enorme aporte que en épocas pasadas hacían los ríos por ciclos de dinámica fluvial que llegan a esta zona, así como por la acción que cerca de la costa puede tener el modelado costero por influencia del mar.

Peligros potenciales naturales asociados con estas morfologías:

F5: inundaciones en los sectores recorridos por el río dentro de la planicie aluvial. Influencia directa de eventos meteorológicos por huracanes.

\section{F9. Pantano permanente o temporal}

La subunidad pantano permanente o temporal se sitúa en secciones aisladas dentro de la llanura aluvial y en forma continua y extendida a lo largo de la zona litoral a manera de transición entre el relleno continental y los cordones litorales que conforman la línea de playa.

Constituyen zonas de terreno plano que suelen tener un micro relieve de pequeñas ondulaciones. La unidad se compone de un relleno de fragmentos líticos muy finos, con dominancia de arcilla y limo y pequeños lentes arenosos; su origen se debe a rellenos por aportes fluviales

Peligros potenciales naturales asociados con estas morfologías:

F9: inundaciones. Influencia directa de eventos meteorológicos por huracanes.

\section{F13. Lagunas endorreicas}

Aunque ya no con tanta profusión, debido en principio a las actividades de laboreo de las tierras de la llanura aluvial, es posible aun identificar sectores con depresiones ocupadas por cuerpos lagunares. Estos cuerpos de agua aparecen a lo largo de lechos fluviales de ríos como Parismina, Aguas Zarcas, Reventazón y Pacuare. Su morfología en general responde 
a lo divergente de la dinámica fluvial meándrica y que se expresa como lagunas en forma de media luna. Mención particular merece la Laguna Cuatro (coord. 234-502) que aparece caracterizada como tal en la hoja topográfica Matina 1:50.000 de 1962. En la actualidad su denominación se enmarca como un pantano permanente o temporal, ya que el espejo de agua ha cedido paso a vegetación espesa.

\section{M1. Cordones litorales}

La unidad litoral de origen marino está constituida por cordones litorales y lagunas del Caribe norte; los cuales dentro de los límites del cantón se sitúan entre el poblado de Parismina, a la desembocadura del río del mismo nombre, y boca del estero Madre de Dios.

Su superficie es plana horizontal, con una altura promedio de cinco metros sobre el nivel del mar. La playa se encuentra en su forma natural, como parte del relleno litoral que tierra adentro está seccionado y limitado por un canal o laguna litoral. Esta unidad se compone de relleno de playa y, por consiguiente, las fracciones líticas más abundantes son las arenas, con lentes y laminillas delgadas de limos y arcillas que se intercalan sobre todo en las áreas cercanas a la desembocadura de los ríos. Su origen se debe a la interrelación de las corrientes marinas litorales y los fragmentos líticos que son arrastrados por ellas. Estas partículas se mueven paralelas a la costa y son depositadas. Con el tiempo el relleno crece tanto que emerge. A partir de este momento gana altura por el acarreo de partículas por el viento; y a consecuencia de lo anterior, queda separado un brazo de mar que se transforma en el canal o laguna litoral. La edad de estos acúmulos litorales es del Cuaternario y posiblemente del Plio-Pleistoceno (Madrigal, 1980).

Peligros potenciales naturales asociados con estas morfologías:

M1: inundaciones y erosión litoral por oleajes. Influencia directa de eventos meteorológicos por huracanes.

\section{F1.a, F1b, F1c, F1d. Abanicos aluviales activos}

En correspondencia con los procesos de depósito en las áreas que marcan la transición entre la zona montañosa y la planicie, se distinguen acúmulos de material correspondientes al abandono que hacen los cursos fluviales de la zona montañosa. Esos depósitos producto de la erosión de relieves aguas arriba y de su transporte originan formas amplias y de suave 
pendiente que se explayan a su ingreso a terrenos planos y no confinados como los cauces que los transportan desde las secciones altas de las cuencas. En el presente caso de oeste a este, la comunidad de Pacuarito se asienta sobre una de estas formas denotada como F1a. Los cursos fluviales que originan este depósito son la quebrada Leona, el río Pacuarito y la quebrada Espavel. Los tres se unen unos 1000 metros antes de ingresar al sector de Pacuarito por el oeste.

Desde aquí el acúmulo continúa hacia el este por unos 3000 metros, en forma de una angosta faja (F1b) que establece una transición en cuanto a pendiente entre el área montañosa y una parte del sector plano que a su vez sirve de área de paso para la vía férrea y la carretera que lleva a la ciudad de Limón.

En esta porción longitudinal que sirve de asiento a las comunidades de Freehold y Monteverde, así como Culpepper, tres pequeñas quebradas de trayectoria que no exceden los 2 kilómetros de longitud y que se funden en la quebrada Rosita descienden por un fuerte flanco montañoso que se ubica al sur. Por la anchura del depósito no existe fuerte correspondencia entre la acumulación y procesos erosivos que evidencien una fuerte dinámica en las secciones altas de estas quebradas. Más bien de la disposición longitudinal de la forma y paralela al borde montañoso se deduce que los materiales ahí depositados han sido transportados por procesos normales ocasionados por la erosión laminar y aportes por desprendimientos.

El desarrollo de la forma continúa extendiéndose hacia el este hasta ampliarse gradualmente para servir de asiento a la comunidad de Santa Rosa (F1c). La morfología aquí adquiere la apariencia lobulada típica de un abanico aluvial convexo. Esta sección constituye la parte de la sección lateral oeste de un abanico aluvial más extenso que se desarrolla hacia el este (F1d) y que tiene como ápice el río Madre de Dios. En verdad la forma F1c puede considerarse como una forma con dinámica propia ya que, si bien se asocia por vecindad y homogeneidad morfológica con el río Madre de Dios, tiene como aportador fundamental de su depósito al río Cimarrones. Este curso fluvial lo disecta y se constituye junto con el F1d en una coalescencia de dos abanicos aluviales en principio.

La sección delimitada como F1d representa en particular el abanico aluvial más extenso de esta parte de Siquirres lindante con el cantón de Matina, extendiéndose incluso más allá del límite administrativo que establece 
el río Madre de Dios. Su área sobrepasa los $15 \mathrm{~km}^{2}$ para ambos cantones, siendo este último curso fluvial el que establece la principal dinámica de depósito. El abanico es activo, ya que la dinámica fluvial desarrolla un patrón anastomosado con formación de cauces secundarios activos y abandonados, lo cual disecta el depósito aluvial en profundidad apreciable.

Sobre estas morfologías, respectivamente, se ubican los poblados de Cimarrones, Río Hondo y Madre de Dios.

Peligros naturales potenciales asociados con estas morfologías:

F1a: inundaciones, localidades afectadas Pacuarito.

F1b: inundaciones y avalanchas súbitas; localidades afectadas: Freehold y Monteverde.

F1c: inundaciones comunidad de Santa Rosa y Cimarrones.

F1d: viviendas construidas en sección distal de abanico.

Áreas adyacentes a los ríos Cimarrones y Madre de Dios.

\section{F2. Lomerios bajos}

Bajo esta denominación se incluye un grupo de relieves de altitudes que no sobrepasan los 90 metros de altitud. Estas topografías se ubican dentro de la extensa área de influencia distal de una de las formas comentadas atrás bajo los códigos F1d y F1c y que tienen como origen de aporte sedimentario los ríos Cimarrones y Madre de Dios. Los relieves en cuestión se consideran como relictos de relieves asociados a la sedimentación aluvial que ha determinado el paisaje actual. Estos relieves, en proporción de mayor altitud que la planicie circundante producto del depósito en los abanicos, constituyen plataformas plano-inclinadas de muy escasa pendiente y que a manera de suaves elevaciones sobresalen dentro de la platitud que caracteriza el sector. La presencia de estos lomeríos evidencia por su extensión un proceso activo de formación de nuevas tierras y que se mantiene vigente en la actualidad. La extensividad y potencia de estos abanicos aluviales relictos se hace patente localmente cuando se observa que, partiendo de la curva de nivel de 30 metros que marca la sección más distante de estas paleoformas, se requiere recorrer aproximadamente 500 metros para situarse sobre la subsiguiente cota de altitud de 20 metros.

Estos desniveles no muy apreciables en los mapas topográficos sí establecen diferencias topográficas significativas con relación al volumen de material que se transportó por estos ríos. 
Contenida parcialmente dentro de esta forma y en la extensa planicie de la llanura que la limita por el norte se localiza la laguna Cuatro. Esta laguna endorreica representada en documento cartográfico antiguo como un cuerpo de agua definido se halla enteramente cubierta por vegetación en la actualidad. Su presencia parcial en la parte más extrema de la forma F2 y en la transición con el sector plano de la llanura indica con precisión la presencia de micro relieves y desniveles debidos a depósitos aluviales antiguos.

Peligros naturales potenciales asociados con estas morfologías:

F2: inundaciones al paso del río Hondo.

\section{Unidades de origen tectónico y erosivo}

De acuerdo con Madrigal (1980) las formas así agrupadas deben su origen al movimiento ascendente y la subsiguiente erosión.

La Cordillera de Talamanca ejemplifica esta unidad. La totalidad del sector montañoso y de alta pendiente que caracteriza al cantón de Siquirres por el sur está contenido dentro de esta unidad.

Constituye el eje del país desde la parte central hasta la frontera con Panamá. Ocupa a su vez la mitad sur del país, internándose en territorio panameño. Tiene valles profundos con laderas de pendiente fuerte. Las divisorias son angostas. Su estructura es complicada por la presencia de pliegues y fallas. Las rocas más viejas de esta cordillera parecen ser las de la Formación Tuis y Brito, del Eoceno y como rocas más jóvenes se encuentran las de Suretka de edad Plioceno. Intrusiones ácidas y básicas son frecuentes en la cordillera, así como rocas volcánicas. La meteorización es muy profunda en todas partes, dependiendo desde luego de la pendiente del terreno. La forma de la cordillera está grandemente influenciada por la presencia de fallas y pliegues, lo mismo que por la diversidad de rocas. Su origen se debió a una sedimentación marina que ocurrió hasta el Mioceno Medio, luego se inició un ascenso y plegamiento durante el Mioceno Medio al Superior. Posteriormente un plutonismo con magmas ácidas y básicas originando las intrusiones, el cual es muy posible que llegó hasta el Plioceno (ídem).

Tal y como se apuntó atrás, una tercera parte del territorio de Siquirres se ubica en las estribaciones de la Cordillera de Talamanca que dan hacia el Caribe. La interacción entre esta sección montañosa y los relieves planos propios de la llanura aluvial que conforman la otra parte del paisaje 
de este cantón es intrínseca. Ambos paisajes representan una continuidad en el ciclo que origina y transforma nuevas tierras La dinámica denudativa de la sección alta repercute en la sección baja. Así, es posible hallar aquí una gran diversidad de morfologías cuya evolución tiene claro impacto en las tierras bajas.

Las formas denudativas que a continuación se describen bajo la inicial D se ubican en la Cordillera de Talamanca.

\section{Formas originadas por remoción en masa}

\section{D5 y D5a. Deslizamiento}

Madrigal (1980) denomina esta forma como deslizamiento en Lajas y Chitaría de Peralta y lo cataloga como semi activo. Se ubica en el valle medio del río Reventazón, entre la jurisdicción de Turrialba y Siquirres. Si bien por pertenencia cantonal, la forma queda mayormente comprendida en Turrialba, lo cierto es que su localización en ambos costados de valle del Reventazón y la orientación de las aguas hacia este colector principal hacen que este canal actúe como medio natural para el transporte de sedimentos eventualmente removidos de este deslizamiento.

La forma en sí es muy extensa y espectacular, no solo por las dimensiones que ocupa (unos $30 \mathrm{~km}^{2}$ ), sino porque su ubicación dentro de formaciones geológicas constituidas por materiales altamente inestables confiere imprecisión al momento de establecer

claramente sus límites. Aquí rocas volcánicas ubicadas en el lado norte del Reventazón y provenientes del volcán Turrialba; sobreyacen sedimentos marinos de las formaciones Uscari y Senosri constituidos por areniscas muy meteorizadas y lutitas arcillificadas, las cuales de hecho constituyen mantos ideales para el movimiento, sobre todo en regiones que, como esta, tienen regímenes de alta pluviosidad.

La morfografía destaca por la presencia de lomas transversales a la pendiente, así como superficies irregulares y desordenadas, con drenajes no ajustados a un patrón definido. Los costados de los valles de los ríos Pascua, Bonilla, Roca y Blanco, para citar algunos, se observan fuertemente disectados y con huellas erosivas evidentes de procesos continuos de desestabilización. Los valles son muy profundos y conforman dentro del área los sectores más abruptos del cantón. La unidad D5a, localizada 
al este del deslizamiento principal y con el río Reventazón separándolos, tiene características de menor espectacularidad que la D5 esencialmente por el territorio que abarca. Esta es una unidad que posee una divisoria de aguas principal y de cima relativamente amplia. Las laderas a ambos costados de esta divisoria son de pendiente moderada advirtiéndose mayor grado de disección aparente en la ladera este. No se observa la topografía caótica de su homóloga al oeste, aunque sí se advierten secciones de terreno basculados y discontinuidades topográficas en las laderas, con cursos fluviales medianamente entallados.

Poblados como Altos Pascua (San Isidro), San Antonio, Pascua (San José), Bonilla son algunos de los núcleos poblacionales que tienen su asiento en esta área. En la D5a: poblados como Bajo 52 millas, Calvario, Encanto, Ganga y la Amistad.

Peligros naturales potenciales asociados con estas morfologías:

D5: remoción en masa, avalanchas súbitas, caída de rocas.

D5a: reptación, inundaciones y avalanchas súbitas.

D6a. Relicto superficie semiplana erosionada alta

D6b. Relicto superficie semiplana erosionada baja

D6c. Relicto superficie ondulada

D6. Relicto superficie irregular colgada

Esta unidad (D6a) constituye un remanente morfográfico de las superficies que alguna vez quizás constituyeron secciones estables del deslizamiento que se comentaba atrás. Ocupa sitios cimeros circundados por terrenos inestables y de cuyos flancos se originan impresionantes taludes de erosión hacia los ríos Gallina y Pascua al norte y Susto y Bonilla al sur; así como hacia la quebrada Linda y Hermosa al este. Las pendientes son de suaves a moderadas y la topografía va de tierras onduladas a sectores plano-inclinados. Es disectada levemente por parte de los dos últimos cursos fluviales que se nombran. La apariencia morfográfica a distancia se asemeja a una inmensa terraza de territorio suspendido mediante paredes verticales.

A lo interno de esta unidad se reconoce una segunda morfología que aquí se denomina D6b,siendo en principio la quebrada Hermosa el accidente natural que las separa. A simple vista ambos territorios son similares y en efecto lo son, con la salvedad de que la unidad D6b se halla desplazada 
verticalmente de la D6a por un escarpe de 2500 metros de longitud, el cual se ensancha gradualmente de oeste a este para alcanzar así una diferencia altitudinal de unos 80 metros.

A simple vista ambas morfologías se asemejan a los cortes característicos que efectúa la acción erosiva de los ríos en sus riberas, lo cual origina terrazas.

El desplazamiento vertical que experimenta esta unidad D6b podría primero deberse a la inestabilidad propia de terrenos con problemas generalizados por movimiento de laderas $\mathrm{u}$ originarse realmente por el corte fluvial que establece el río Blanco que la limita al norte. La justificación de esta hipótesis tiene asidero por cuanto la unidad D6c, ubicada inmediatamente al norte del río Blanco, tiene cierta correspondencia topográfica y altitudinal con la superficie D6b. En realidad, ambos territorios son disectados fuertemente por el río Blanco, así como por las profundas gargantas que forman los ríos Pascua, Roca y Gallina.

Ambas unidades poseen rasgos morfológicos similares, aunque la D6c se diferencia de la D6b porque posee mayor irregularidad en su relieve y solamente un amplio sector plano inclinado cuya similitud con las tierras al sur del río Blanco se destacó atrás. La unidad D6c limita por el oeste con el río Destierro el cual a su vez establece el límite cantonal en ese sector.

La unidad D6 conforma un territorio a manera de pequeño escalón que se ubica entre el extremo este de la unidad D6a y el río Bonilla. Por su similitud topográfica representa un segmento colgado de la D6a, delimitado hacia el oeste de esta por un escarpe en forma de

semicírculo que pertenece al topónimo del cerro Encanto. Esta forma posee una topografía irregular y con un fuerte talud de erosión hacia el río Bonilla el cual discurre unos 100 metros ladera abajo por un valle fluvial fuertemente entallado. Por su fisiografía, esta forma parece representar una de las tantas superficies de instabilidad contenidas dentro del grupo de estas formas denudacionales y que conforman a manera de un inmenso mosaico un vasto territorio afectado por inestabilidad de laderas.

Poblados como Destierro, Roca, Altos Pascua (San Isidro) tienen su asiento aquí.

Peligros naturales potenciales asociados con estas morfologías:

D6a, D6b, D6c, D6: deslizamientos en flancos de valles fluviales e inestabilidad generalizada, agrietamientos y reptación. 


\section{D4. Colinas y laderas denudacionales}

Esta unidad morfológica es la más extensa de las delimitadas en la zona montañosa del cantón de Siquirres. Tiene como límite por el oeste el río Reventazón y por el sur parte de la unidad D5a, además del límite cantonal con Turrialba. Constituye una unidad morfológica altamente disectada en concordancia con materiales de las formaciones Suretka del Plioceno y Senosri del Oligoceno. La topografía de esta área responde precisamente a su conformación geológica, es decir, de materiales muy meteorizados, inestables por el efecto lubricante que ejercen las aguas pluviales sobre terrenos arcillificados y, por lo tanto, favorecedores del entalle vertical de los cursos fluviales con interfluvios que van de amplitud moderada a cortos. La forma de las pendientes, por tanto, se corresponde con esta descripción, observándose una combinación de formas cóncavas y convexas, cuya correspondencia se asocia en principio a afloramientos rocosos y a procesos de erosión en áreas en donde la pendiente lo favorezca.

Algunos centros poblados aquí son: Guayacán, Moravia, Linda Vista, Bajo Tigre, Pascua (San José) y Coco.

Peligros naturales potenciales asociados con estas morfologías:

D4: reptación, inestabilidad de laderas en áreas adyacentes a ríos.

\section{D3. Superficies elevadas disectadas}

La unidad D3 se localiza fragmentada en cuatro secciones que se ubican tres entre el río Reventazón y el Madre de Dios y una en la margen derecha del primero. La totalidad de ellas comparte, sin embargo, el ocupar terrenos mayoritariamente constituidos por cimas aisladas de altitud escasa y divisorias de aguas de difícil definición. Estos rasgos tienen la particularidad de que, dentro de la irregular topografía que les rodea, estas constituyen secciones amplias, con intercalaciones de sectores ondulados, pendientes largas y medianamente disectadas en comparación con los terrenos que las delimitan. Estos territorios son remanentes de áreas fuertemente afectadas por erosión fluvial. Algunas de estas secciones constituyen también flancos de laderas de pendientes moderadas y no tan quebradas como los profundos valles fluviales que se desarrollan en su periferia.

Peligros naturales potenciales asociados con estas morfologías:

D3: deslizamientos, erosión fluvial. 
Figura No.1. Ejemplo de paso de detalle estereoscópico a mapa

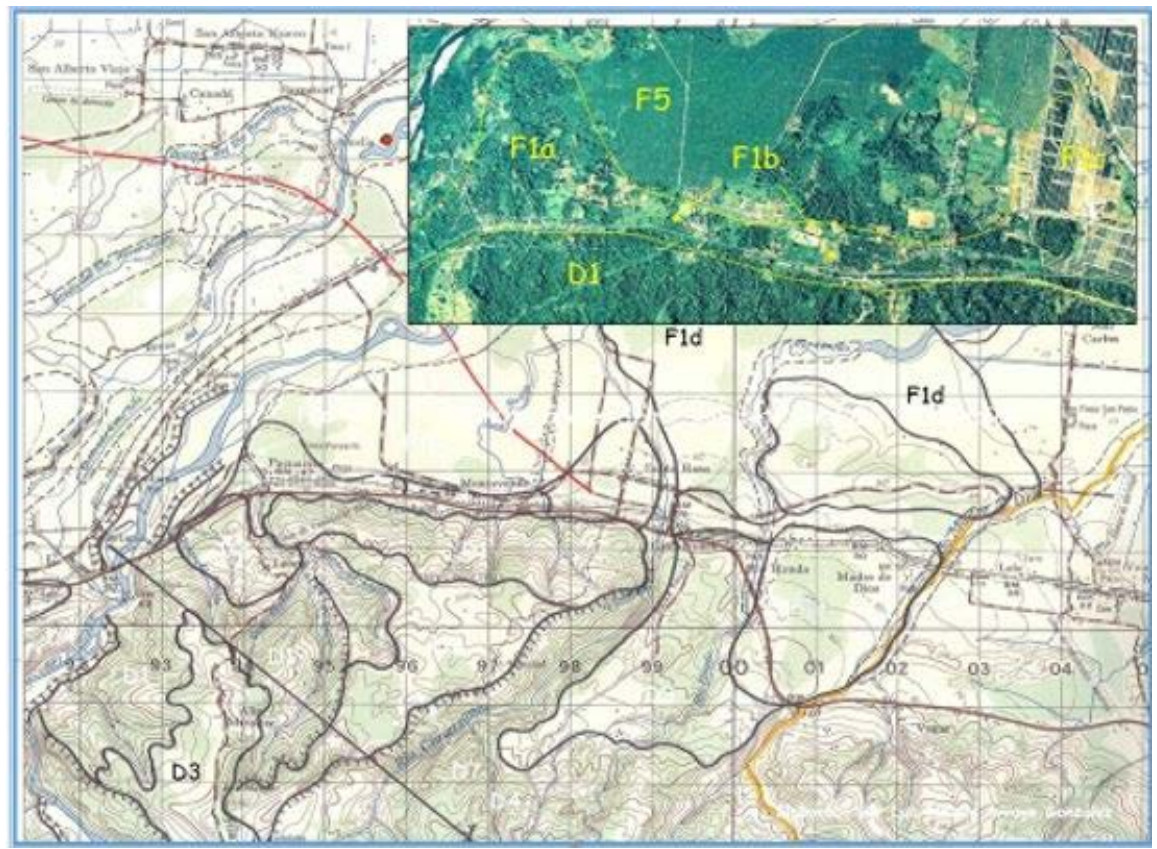

\section{F6. Terraza de erosión elevada}

Esta forma se localiza a unos 160 metros de altitud, en esta parte con respecto al río Reventazón. Es una superficie plana, ligeramente inclinada, no disectada y que contrasta por su platitud con las formas que se identifican en esta sección del territorio. Se encuentra delimitada por taludes de erosión imponentes y su aspecto topográfico destaca frente a la irregularidad y grado de disectación de los relieves que le rodean. No tiene correspondencia altitudinal evidente con territorios vecinos. Su origen parece deberse a la acción erosiva del río Reventazón.

Peligros naturales potenciales asociados con estas morfologías:

F6: inestabilidad de laderas en áreas adyacentes a los taludes de erosión.

\section{F7. Terraza elevada muy erosionada}

La unidad F7 rodea prácticamente a la analizada en el apartado anterior. A diferencia de aquella, este territorio es altamente disectado, recorrido por una topografía muy irregular y con lomas transversales a la pendiente. Contenidas aquí se encuentran las lagunas Bonilla y Bonillita, ocupando la 
segunda una posición de mayor altitud con respecto a la primera. En áreas de inestabilidad de laderas ambos rasgos pueden tener correspondencia con las depresiones que se rellenan de agua y que se forman a raíz del movimiento diferencial de masas de material. Quizás también en un periodo esta unidad fue afectada por procesos erosivos y de depósito fluvial originados por el río Reventazón, ya que se observan terrenos semiplanos en las vecindades de las lagunas, especialmente inmediatamente al sur de la Bonillita.

\section{F4, F4a y F3. Terrazas fluviales}

Las unidades F4 y F4a representan depósitos de materiales aluvionales que se localizan a lo largo de varias secciones del cauce del río Reventazón, mientras que la denominación F3 identifica depósitos similares que se asocian al río Pacuare. Las denominadas F4 se ubican a nivel del cauce principal mientras que la F4a se encuentra a mayor altitud. Este último rasgo no se halla continuo a lo largo del curso fluvial, sino que el corte que efectúa el río y que en algunas partes se expresa en un escarpe que alcanza los 160 metros de altitud se realiza a partir de la quebrada Cuarenta y Cinco (228-581), ubicada en la margen oeste del Reventazón y se prolonga por unos 6 kilómetros aguas abajo hasta el denominado Codo del Diablo. La correspondencia entre este corte y la unidad D4 al este difiere sustancialmente del que el mismo río realiza en la margen oeste, ya que, en el primer caso, las pendientes que se orientan hacia el río presentan en general un gradiente más suave. En cambio, en su margen izquierda, el río realiza un corte sobre potentes depósitos provenientes de un abanico aluvial que tiene como vértice el río Reventazón.

Comunidades en F4: Bonilla Abajo, Lomas, Florida, Casorla, Bajo 52 Millas

Peligros naturales potenciales asociados con estas morfologías:

F4: inundaciones.

F4a: deslizamientos.

F3: inundaciones.

\section{F5. Abanico aluvial}

Parte de esta inmensa unidad se corresponde con el límite administrativo oeste del cantón, definido por el río Destierro. Este curso fluvial representa también el vértice del abanico. La unidad en sí tiene pendiente 
suave y de forma convexa en general. Tiene un patrón de drenaje dicotómico que se expresa en una densidad de drenaje media a alta.

Tal y como se reseñó atrás, parte de su límite este se expresa mediante un profundo corte que realiza el río Reventazón y que separa esta forma de la unidad de colinas y montañas denudacionales (D4).

Algunas comunidades asentadas aquí son: Vueltas, Río Peje, Alegría, Finca Florida, Altos Herediana (San Isidro), Francia, Babilonia, Germania, Cairo, Trinidad y Louisiana, entre otras.

Peligros naturales potenciales asociados con estas morfologías:

F5: inundaciones, sección distal.

\section{F12. Abanico aluvial activo}

Esta unidad sirve de asiento a la ciudad de Siquirres y ha sido formada por los depósitos aluviales provenientes de procesos de erosión ocurridos a lo largo de la cuenca hidrográfica del río homónimo. En comparación con unidades morfológicas similares presentes en el cantón, esta carece de la extensión y el volumen que aquellas poseen, ya que a lo mucho cubre unos dos kilómetros cuadrados de área. Su forma es convexa, de pendientes suaves y laderas ligeramente inclinadas.

Peligros naturales potenciales asociados con estas morfologías:

F12: inundaciones en la ciudad de Siquirres.

\section{D1. Talud de erosión}

Esta forma se ubica dentro de la unidad D4 (colinas y montañas denudacionales) y corresponde a una sección del curso medio del río Pacuare. Representa un sector fuertemente disectado, de laderas rectas y cortas, definiendo para el río en este sector un valle fluvial angosto.

Peligros naturales potenciales asociados con estas morfologías:

D1: deslizamientos.

\section{D7. Escarpes}

Estos rasgos morfológicos representan formas aisladas que se localizan principalmente en la unidad D4 (colinas y montañas denudacionales). Se comentan por aparte ya que las rupturas de pendiente que representan evidencian procesos erosivos intensos y áreas en donde las laderas adquieren fuertes grados de inclinación. 
Peligros naturales potenciales asociados con estas morfologías:

D7: deslizamientos.

\section{Formas de origen estructural}

\section{E1. Falla de Tigre (Fallas y/o alineamientos geológicos)}

Madrigal (1980) sitúa esta forma a 3 kilómetros al sur de la ciudad de Siquirres, entre el sector comprendido al noroeste del poblado Linda Vista y Alto Berlín, De acuerdo con la descripción que efectúa, se dice que "tiene una longitud de ocho kilómetros con un rumbo de $\mathrm{N} 38^{\circ} \mathrm{E}$. Caracterizan la traza de esta falla en superficie escarpes de hasta 500 metros y pendientes de más de $30^{\circ}$. Las rocas cortadas o intersectadas por esta falla son principalmente sedimentarias, pertenecientes a las formaciones Uscari y Senosri; areniscas, gran cantidad de lutitas muy plásticas y ocasionalmente alguna caliza. Todas se encuentran muy meteorizadas y en superficie" (p.61).

Peligros naturales potenciales asociados con estas morfologías:

E1: deslizamientos.

\section{E2. Fallas varias (y/o alineamientos geológicos)}

Se incluyen aquí aquellos rasgos estructurales que aparecen en la cartografía de la Comisión Nacional de Emergencia (CNE, 1994). Estas se expresan en los mapas topográficos.

\section{Resumen sobre las aptitudes de las unidades geomórficas}

Un 70\% del cantón se origina por procesos de origen fluvial. Este territorio se subdivide a su vez en tres unidades. La F8b se corresponde con terrenos planos, localizados bajo la curva de nivel de los 10 metros como es una unidad inmediatamente vecina al mar, o puede mostrar influencia salina en sus suelos. La unidad F8a representa la sección media de esta unidad y posee tierras arriba de los 10 metros de altitud. Es plana con un ligero grado de inclinación (de $0 \%$ a $8 \%$ ) y aunque se encuentra más elevada que la anterior, presenta también problemas de inundabilidad aunque sin influencia salina.

Aquí no se halla profusión de área con lagunas endorreicas como si se hallan en la anterior. La tercera sección corresponde con la unidad 
denominada abanico aluvial. Esta área es la que presenta menos limitaciones de las tres, ya que representa la unidad de mayor altitud y la de menos declive por lo que no tiene problemas de inundabilidad como las anteriores y presenta características en donde no se advierten limitaciones debido a sus propiedades naturales. Su pendiente es suave (de 0\% a 8\%) pero al tener mayor declive por ser más corta que las demás, sus aguas poseen capacidad de escorrentía mayor sin que eso signifique problemas menores por inundaciones o encharcamientos.

El restante $30 \%$ del cantón se encuentra dominado por formas de origen denudativo, las cuales se identifican con la inicial D. De las unidades así identificadas, la que presenta mayores restricciones es la que se denomina "deslizamiento semiactivo", el cual ocupa 47,20 $\mathrm{km}^{2}$. Esta área tiene muchas limitantes y su uso se enfocaría principalmente como áreas de conservación con una densidad muy baja en construcciones, ya que, si bien es extensa, la realidad es que todo el sector tiene casi en su totalidad pendientes fuertes $(30 \%$ a $60 \%)$ y se halla fuertemente afectado por procesos de inestabilidad de laderas, por lo que las áreas presentan quebraduras, lomas transversales, taludes de erosión activos en los costados de los valles fluviales y, en general, una topografía caótica. Su uso se enfocaría en conservación de bosques para fines ecoturísticos porque los paisajes son muy bellos y la presencia en sectores de una densa vegetación favorece un turismo de esta naturaleza. Sin embargo, la sección denudada que se acerca más a estos fines es la $\mathrm{D} 4$, ya que no presenta problemas tan evidentes de erosión e inestabilidad, pues en general es forestada. La D3 entra dentro de esta categoría, puesto que, si bien presenta ciertos sectores con uso de la tierra extensivo, su vocación tiene menos restricciones que la sección que presenta el deslizamiento. La unidad denominada D1 y que se ubica una parte al sureste de Siquirres se caracteriza por una pendiente fuerte hacia las denominadas F1a, F1b, F1c, F1d y F12; presentan pequeños abanicos aluviales con comunidades en sus vecindades. Sobre el F12 se asienta la ciudad de Siquirres, así que como el poblado de Pacuarito y algunos pequeños poblamientos paralelos a la carretera que lleva a Limón. Las áreas adyacentes a estos sectores, sobre todo los pequeños ríos que las forman, deben ser protegidas en sus cuencas y fomentar programas de conservación de bosques (Mapa No.2 y No.3). 
Luis Nelson Arroyo González Geomorphology of the canton of Siquirres, Costa Rica

Mapa No. 2. Estimación territorial de unidades geomorfológicas principales.

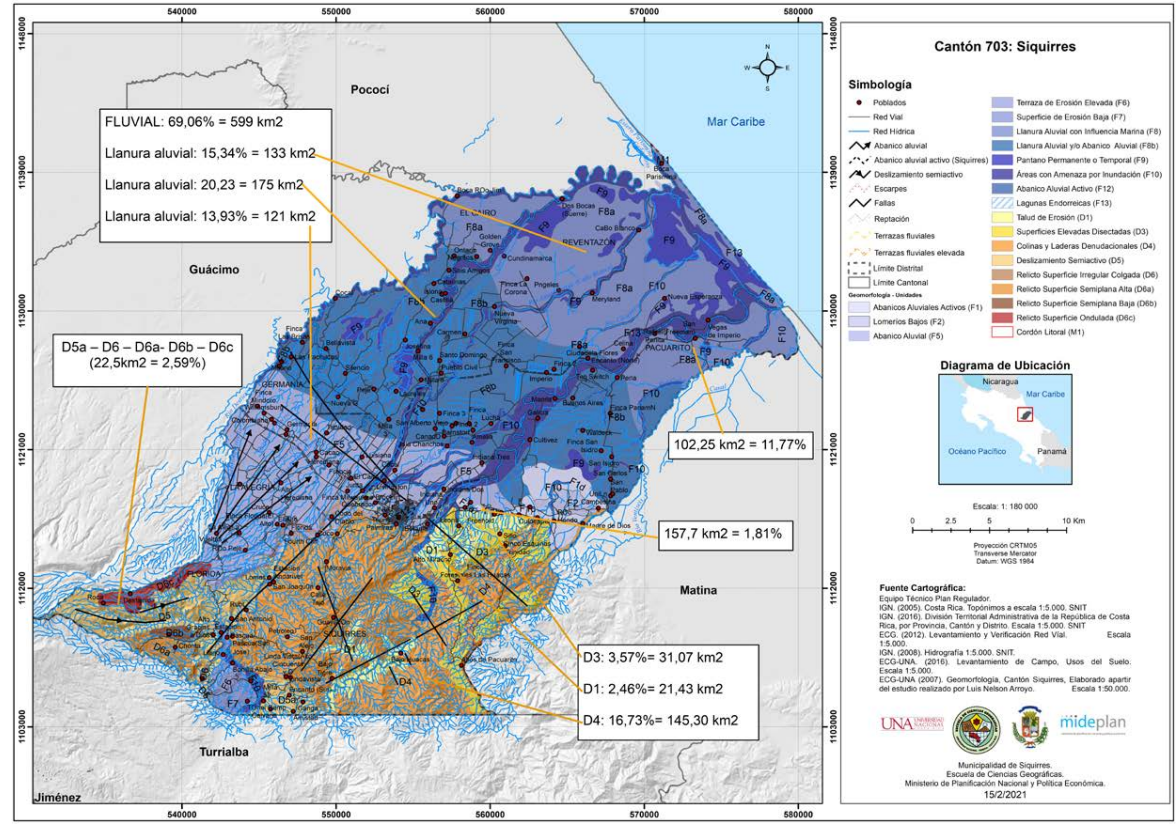

Mapa No. 3. Unidades geomórficas versus territorio cantonal en $\%$.

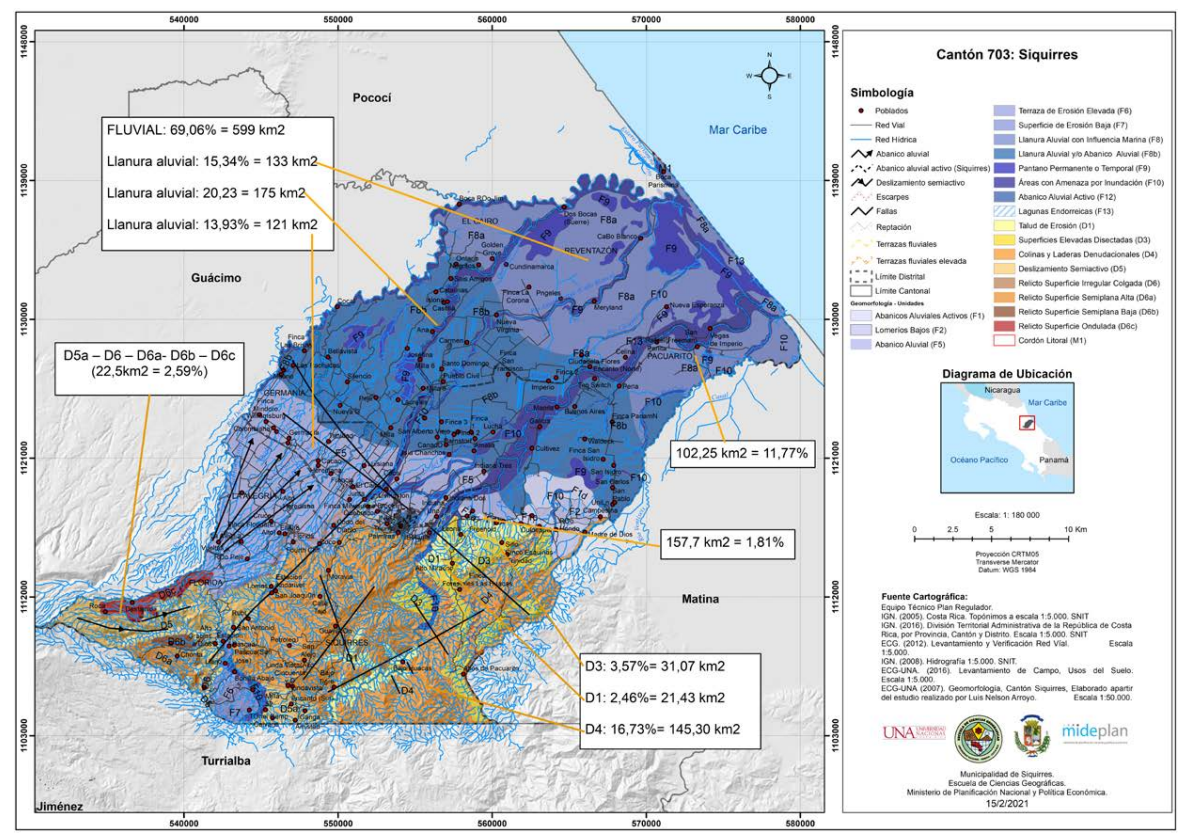

238 Revista Geográfica de América Central. No 68(1)

ISSN 1011-484X • e-ISSN 2215-2563 / Enero-junio 2022 
Luis Nelson Arroyo González

Geomorfología del cantón de Siquirres, Costa Rica

\section{Referencias}

Comisión Nacional de Prevención de Riesgos y Atención de Emergencias. (CNE) (1994). Sistema de Información para Emergencias (SIE). Recuperado de: http://www.cridlac.org/digitalizacion/pdf/spa/doc7228/ doc7228.htm

Instituto Geográfico Nacional. (1998). Fotografías aéreas de líneas 35A, $36 A, 37 B, 38 B$ y 39B. Proyecto TERRA, escala 1:40.000.

Instituto Geográfico Nacional. (1967). Hojas topográficas Tucurrique, Matina, Barbilla, Parismina, y Bonilla, escala 1:50.000.

Madrigal, R. (1980). Manual Descriptivo del mapa geomorfológico de Costa Rica. (escala 1:200.000). Secretaría Ejecutiva de Planificación Sectorial Agropecuaria y de Recursos Naturales Renovables (SEPSA). San José, Costa Rica: Imprenta Nacional.

Ministerio de Recursos Naturales Energía y Minas. (MIRENEM) (1980). Mapa Geológico escala 1:200.000.

Van Zuidam, R. (1986). Aerial photointerpretation in terrain análisis and geomorphological mapping.The Hague, The Netherlands: Smit Publishers.

Verstappen, H. (1983). Applied geomorphology, geomorphological surveys for environmental development. International Institute for Aerial Survey and Earth Science (I.T.C.), Enschede, The Netherlands. ELSEVIER Amsterdam. 
